\author{
HUMANASE SOCIAIS \\ v.8 • N.3 • 2020 • Fluxo Contínuo \\ ISSN Digital: 2316-3801 \\ ISSN Impresso: 2316-3348 \\ DOI: 10.17564/2316-3801.2020v8n3p136-159
}
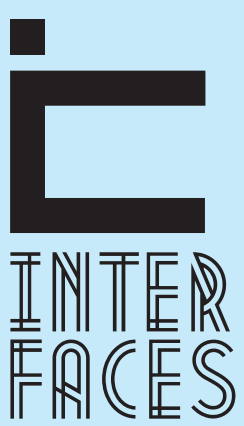

CIENTÍFICAS

\section{CONDIÇÕES DE UM TRABALHO DIGNO NO MANEJO DA CASTANHA NA CIDADE SERGIPANA DE ITABAIANA E OS IMPACTOS DA MODERNIZAÇÃO DAS NOVAS TECNOLOGIAS}

CONDITIONS OF DECENT WORK IN THE MANAGEMENT OF CHESTNUTS IN ITABAIANA AND THE IMPACTS OF MODERNIZATION OF NEW TECHNOLOGIES

CONDICIONES DE UN TRABAJO DECENTE EN LA GESTIÓN DE CASTAÑAS EN LA CIUDAD SERGIPANA DE ITABAIANA Y LOS IMPACTOS DE LA MODERNIZACIÓN DE NUEVAS TECNOLOGÍAS

Alexandro Nascimento Argolo ${ }^{1}$

Fran Espinoza ${ }^{2}$

\section{RESUMO}

Esta pesquisa analisou in loco como se opera o manejo da castanha de caju, em especial, junto as comunidades familiares que trabalham com a cajucultura nos povoados de Carrilho, Dendezeiro e Tabocas, no município de Itabaiana, Sergipe. 0 estudo em questão considerou um tema de pesquisa agrícola brasileiro inserido na dinâmica da agricultura familiar e em crescimento na região Nordeste principalmente na última década: a cajucultura ou o manejo para o beneficiamento da castanha de caju. No estado de Sergipe e de forma particular no município de Itabaiana, a produção da castanha de caju tem apresentado elementos que o diferenciam das demais áreas produtoras desse item no território brasileiro, principalmente no aspecto da tradição e da dinâmica do trabalho familiar no processo de beneficiamento. Quanto à abordagem, a pesquisa é qualitativa, de natureza aplicada e quanto aos seus objetivos trata-se de uma pesquisa exploratória, descritiva e explicativa de fenômenos que vão além do olhar jurídico sobre o objeto. Com procedimento de revisão bibliográfica, documental, realizando pesquisa de campo que levou a reflexão a um locus específico com um olhar etnográfico. 0 principal objetivo é (re)pensar o trabalho rural sob a ótica das novas tecnologias sob o viés do trabalho digno na contemporaneidade.

\section{PALAVRAS-CHAVE}

Trabalho Digno. Meio Ambiente do Trabalho. Novas Tecnologias no Trabalho. Manejo da Castanha. 


\section{ABSTRACT}

This research analyzed in loco how the handling of the cashew nut operates, especially with the family communities that work with cashew in the villages of Carrilho, Dendezeiro and Tabocas, in the municipality of Itabaiana, Sergipe. The study in question considered a theme of Brazilian agricultural research inserted in the dynamics of family farming and growing in the Northeast region, especially in the last decade: the cashew or the handling for the processing of the cashew nut. The research is qualitative, of an applied nature, and as for its objectives, it is an exploratory, descriptive and explanatory research on phenomena that go beyond the legal view of the object. With a bibliographic and documentary review procedure, conducting field research that took the reflection to a specific locus with an ethnographic look. The objective of this research is (re) thinking rural work from the perspective of new technologies under the bias of decent work in contemporary times.

\section{KEYWORDS}

Decent Work. Work Environment. New Technologies at Work. Handling of Chestnut.

\section{RESUMEN}

Esta investigación analizó in loco como se maneja el proceso de la castaña de cajú (anacardium occidentale), en especial, junto a las comunidades familiares que trabajan con la cultura del cajú en las poblaciones de Carrilho, Dendezeiro y Tabocas, en el municipio de Itabaiana, Sergipe. El estudio consideró un tema de investigación agrícola brasileño dentro de la dinámica de la agricultura familiar y en crecimiento en la región Noroeste en las últimas décadas: la cultura del cajú o manejo de la castaña de cajú. Se utiliza método cualitativo, de naturaleza aplicada de fenómenos, más allá de la visión jurídica. Se realiza revisión bibliográfica, documental, luego observación directa del fenómeno desde una visión etnográfica. El objetivo de la presente investigación es (re)pensar el trabajo rural desde la perspectiva de las nuevas tecnologías bajo el enfoque del trabajo digno en la contemporaneidad.

\section{PALABRAS CLAVES}

Trabajo Digno. Medio Ambiente del Trabajo. Novas Tecnologías en el Trabajo. Manejo de la Castaña. 


\section{INTRODUÇ̧̃̃o}

No Brasil, a cajucultura compõe uma cadeia rural concentrada nos estados do Nordeste, com número significativo de produtores estabelecidos em uma vasta área entorno com grandes unidades e minifábricas ativas de processamento, compondo um parque industrial de volumosas toneladas ao ano de capacidade instalada. Todo esse complexo gera emprego para milhares de famílias no campo e na indústria e beneficia toneladas da castanha a cada ano, atraindo divisas da ordem de milhões de dólares e posicionando a amêndoa da castanha de caju como o maior item na pauta de exportação de frutas frescas do país.

O cajueiro - anacardium occidentale L, é uma cultura perene, nativa do Brasil. Da árvore pode ser obtido um conjunto de produtos, dentre os quais o principal é a castanha de caju de onde se extrai a amêndoa da castanha de caju utilizada como alimento humano em formas variadas. 0 pedúnculo ou pseudofruto, ainda pouco aproveitado, pode ser consumido in natura ou ser utilizado para a fabricação de doces e para a extração de polpas para sucos e outras bebidas, com o bagaço resultante podendo ser utilizado para ração animal, mediante processamento adequado.

Da casca da castanha do caju, por sua vez, é extraído o Líquido da casca da castanha de Caju (LCC), com aplicações nobres em indústrias químicas, como, por exemplo, na fabricação de tintas, lubrificantes e cosméticos. Ainda da casca dos galhos podados da árvore, da folha, da película da amêndoa da castanha de caju ou mesmo do bagaço do pedúnculo pode ser extraído o tanino, composto químico com vastas aplicações industriais, como na substituição do cromo no curtimento de couro, porém a sua tecnologia de extração não é amplamente acessível.

A cajucultura tem grande relevância para a economia do Nordeste, chegando a mobilizar milhares de famílias no campo e na indústria, sendo fortemente influenciada pela dinâmica setorial da castanha de caju, seu principal produto, cuja amêndoa é destinada basicamente para exportação. Dentre os lugares de destaque no manejo para o beneficiamento da castanha de caju, está o município de Itabaiana, no estado de Sergipe. Em especial, três povoados de sua cercania, Carrilho, Dendezeiro e Tabocas, conhecidos em todo o país pela produção de castanhas, a localidade tem aproximadamente $90 \%$ de sua população envolvida no beneficiamento da castanha, que é comercializada para diversas partes do Brasil.

A escolha do município de Itabaiana, Sergipe, para estudo, decorreu da importante participação que ele tem na economia agrícola de Sergipe, representada, principalmente, no tocante a cajucultura. A sede do município de Itabaiana está situada a 188,00 metros acima do nível do mar. 0 município está posicionado na área central do Estado, em pleno centro geodésico e faz limites com Frei Paulo, Ribeirópolis e Moita Bonita ao norte; Campo do Brito e Areia Branca ao sul; Campo do Brito e Macambira a oeste e a Leste com os municípios de Malhador e Areia Branca.

Distante cerca de 56,0 quilômetros da capital, Aracaju, o município de Itabaiana apresenta posição geográfica privilegiada, por estar em uma área de transição entre o litoral e o sertão sergipano, o que contribui para torná-lo uma referência no agreste do Estado. Apresenta condições favoráveis ao desenvolvimento da cajucultura. E em suas cercanias, há mais de 50 anos as comunidades do Carrilho, Dendezeiro e Tabocas, beneficiam castanhas de caju; tradição passada entre as famílias e que 
garante o desenvolvimento destas pequenas comunidades. Resultado de um processo artesanal de torrefação, as castanhas são comercializadas em todo o litoral brasileiro, com um sabor diferenciado e irresistível.

\section{MÉTODO}

Esta pesquisa analisa in loco como se opera o manejo da castanha de caju, em especial, junto as comunidades familiares que trabalham com a cajucultura nos povoados de Carrilho, Dendezeiro e Tabocas, no município de Itabaiana, Estado de Sergipe. Depois de torrar, começa a função repetitiva de quebrar a casca da castanha. 0 trabalho é sério e em silêncio. Só se escuta o som das pequenas batidas do porrete nas castanhas. As condições de trabalho são precárias. Lanternas e candeeiros trazem um pouco de luz para as mesas onde os trabalhadores batem os porretes bem pertinho dos dedos.

Das cascas torradas como carvão, é retirada uma amêndoa saborosa para quem consome, mas que tem gosto amargo de exploração e de exclusão para os trabalhadores. 0 emprego de crianças na quebra da castanha de caju está incluído na lista de piores formas de trabalho infantil, ao lado de atividades como beneficiamento do fumo, do sisal e da cana-de-açúcar. Não se pode aceitar que as crianças continuem nessa situação, mas não basta reprimir, é preciso oferecer alternativas, no mínimo, se (re)pensar quais as políticas, e se existem, para tornar o trabalho relacionado ao manejo da castanha de caju, um trabalho que dignifique as pessoas.

A complexidade do espaço agrário brasileiro permite não apenas refletir diversos enfoques teóricos sobre ele, mas também estudar as diferenças no interior desse espaço. Assim, analisar a realidade da agricultura familiar a partir dos estudos de caso é pertinente. Dessa forma, o estudo em questão considerou um tema de estudo da agricultura brasileira inserido dentro da dinâmica da agricultura familiar e em crescimento na região Nordeste, principalmente na última década: a castanha de caju. Esse produto, que passa por diversas fases de produção-beneficiamento, tem atraído estudos e matérias jornalísticas sobre o que a castanha de caju está provocando no campo, principalmente como fator gerador de empregos e de renda.

Tradicionalmente, como produto do estado do Ceará, maior produtor nacional, a castanha de caju já apresenta certa diversificação em termos territoriais, sendo encontrada em grande escala de produção, além do Ceará, nos estados do Rio Grande do Norte e da Paraíba e em menor escala nos demais estados nordestinos.

A produção e o beneficiamento da castanha de caju, partindo de uma perspectiva não apenas produtivista, mas de seu rebatimento na singularidade do uso do trabalho familiar, toma uma nova dimensão no estado de Sergipe, merecendo ser examinada como mais um produto que se valoriza no mercado interno e que se amplia comercialmente ao mercado externo.

No estado de Sergipe, e de forma particular no município de Itabaiana, a produção da castanha de caju tem apresentado elementos que o diferenciam das demais áreas produtoras desse item no território brasileiro, principalmente no aspecto da tradição e da dinâmica do trabalho familiar no processo de beneficiamento. Foi por meio dessa perspectiva que a presente pesquisa se desenvolve. 
O presente artigo analisa a importância do trabalho familiar no manejo da castanha de caju no município sergipano de Itabaiana, sob a ótica do trabalho digno e da dignidade da pessoa humana. Para tanto, busca a identificação das novas tecnologias para um trabalho digno, aproximando a análise temática das relações de trabalho no manejo da castanha em Itabaiana.

Se inicia repensando o trabalho rural sob a ótica das novas tecnologias, se aborda o manejo e o cultivo da castanha em no município de Itabaiana, estado de Sergipe, tratando-se das relações de trabalho e o problema do beneficiamento da castanha de caju, as associações e mini fábricas nos arredores do munícipio em tela, as implicações do beneficiamento da castanha de caju. Realizando-se ainda, uma breve análise sobre os impactos da modernização das novas tecnologias no manejo da castanha em Itabaiana-SE.

A partir destas caracterizações, evidencia-se o objetivo desta pesquisa, que é (re)pensar o trabalho rural sob a ótica das novas tecnologias e sob o viés do trabalho digno na contemporaneidade.

Quanto aos aspectos metodológicos do desenvolvimento do artigo, em sua abordagem, a pesquisa é qualitativa, de natureza aplicada e quanto aos seus objetivos trata-se de uma pesquisa exploratória, descritiva e explicativa de fenômenos que vão além do olhar jurídico sobre o objeto - o manejo para o beneficiamento da castanha de caju.

Com procedimento de revisão bibliográfica, documental, realizando pesquisa de campo que conduz a reflexão a um locus específico com um olhar etnográfico, lançado sobre os povoados de Carritho, Dendezeiro e Tabocas, no município de Itabaiana, estado de Sergipe.

\section{LEVANTAMENTO DAS INFORMAÇÕES}

As tecnologias sociais buscam a inclusão social e melhoria das condições de vida das populações, fortalecendo a promoção do bem-viver e o cuidado coletivo com a vida na terra e em nosso país. Nesse sentido, o tema das novas tecnologias para um trabalho digno vem ganhando uma importância muito grande no debate sobre a construção de uma sociedade mais justa, igualitária, solidária e sustentável.

Na medida em que transforma a natureza, criando os produtos de suas necessidades, o homem planta e resolve a terra, dando-lhe um outro significado em consequência de seu cultivo: a escolha do que nela será plantado, da técnica, das ferramentas e da relação de trabalho[...]. (ROSSINI, 2009, p. 6).

O homem utiliza de seu poder de transformar o espaço para elevar o desenvolvimento de uma dada área. Assim, contribui não somente para si, mas para toda uma sociedade dependente dessas transformações espaciais.

A partir das tecnologias utilizadas para o desenvolvimento do campo ou de toda uma rede urbana fornecida pelo capitalismo, sendo o resultado direto de uma modernização, capaz de aumentar sua margem de lucro e manter seu foco sobre uma prosperidade de crescimento.

Essencial e fundamental à esta pesquisa foram os relatórios do Grupo de Pesquisa sobre transformações no meio rural, ligados ao Núcleo de Pós-Graduação em Geografia da Universidade Federal de 
Sergipe (UFS) e liderados por Costa (2009; 2012). Em consequência de seus levantamentos, a partir destas referências é que este último capítulo apresenta reflexões sobre o manejo da castanha em Itabaiana - SE.

É preciso esclarecer as razões pelas quais se tomou como base dados que não são considerados primários no que se refere ao levantamento da pesquisa. Inicialmente se pretendia um levantamento de dados estatísticos e informativos por meio de entrevistas junto às cooperativas da região de Itabaiana-SE, no sentido de dimensionar o manejo e o beneficiamento da castanha de caju na cajucultura familiar da região.

No entanto, a busca pelo levantamento de dados in loco, apresentou-se como uma barreira, ao menos na forma originalmente pensada. A impossibilidade de acesso às informações junto às cooperativas, fez com que a metodologia fosse diversificada, passando de uma forma primária para uma coleta secundária. E nesse sentido, o acesso aos estudos do Grupo de Pesquisa da cajucultura da UFS, foi fundamental, como base dos dados coletados em versão secundária, para o qual se teve o total e irrestrito apoio fundamental da UFS.

Analisou-se in loco como se opera o manejo da castanha de caju, em especial, junto a própria comunidade familiar que trabalha com a cajucultura nos povoados de Carrilho, Dendezeiro e Tabocas, no município de Itabaiana, estado de Sergipe. E como resultado. a experiência pessoal de vivência demonstrou a precarização do trabalho de beneficiamento da castanha de caju, a percepção de trabalho indigno no manejo da cajucultura é a conclusão da verificação in loco da temática abordada pela pesquisa, de modo a não refutar quaisquer entendimentos da importância e da dimensão de se refletir sobre a problemática apresentada.

No experimento de verificação em campo de pesquisa do manejo e do beneficiamento da castanha de caju, foi possível identificar todos as complexidades das atividades e as condições indignas do tipo de trabalho aqui refletidas. Constatou-se que toda a cadeia produtiva de extração do caju é familiar e são utilizadas tecnologias quase primitivas de trabalho, sem o menor cuidado com a saúde dos trabalhadores, bem como a clareza de condições indignas de trabalho de crianças e adolescentes. Não existem condições mínimas de trabalho digno. É possível se afirmar que não existem políticas públicas que asseguram condições mínimas dignas de trabalho no que concerne o manejo da cajucultura.

\section{ANÁLISE DAS INFORMAÇÕES: A URGÊNCIA NO CREJPENSAR DO TRABALHO RURAL SOB A ÓTICA DAS NOVAS TECNOLOGIAS}

Quando se aborda o desenvolvimento rural, tende-se a associá-lo à modernização da agricultura e, em decorrência ou incorporação de novas tecnologias, ao processo produtivo do trabalho rural.

A mudança tecnológica é compreendida como uma utilização de novas técnicas ou novas tecnologias em qualquer processo produtivo, também, em busca de melhorias na utilização dos fatores de produção, vistos como uma forma de modernização.

As tecnologias representam frutos e realizações da civilização moderna, na qual a população por meio 
destas inovações consegue alavancar o mercado e proporcionar o crescimento econômico gerando processos produtivos de comercialização bem como a reprodução social (SCHNEIDER; MENEZES, 2014).

A tecnologia está associada aos resultados econômicos que impactam uma comunidade, resultantes da aplicação de novos materiais, processos ou métodos nos meios de produção. A tecnologia pode ser vista, também, como o conjunto ordenado de conhecimentos empregados na produção e comercialização de bens e serviços, que é intimamente integrado não somente por conhecimentos científicos, provenientes das ciências naturais, sociais, humanas, mas igualmente por conhecimentos empíricos que resultam da cultura, da tradição, das observações e experiências.

A tecnologia, portanto, é um componente da cultura, quando alçada ao debate sobre o trabalho, assume função importante nos aspectos relacionados à melhoria das condições de vida, em especial na sobrevivência das famílias e o aumento do tempo de lazer e descanso.

Tais situações realçam a importância dos aspectos sociais da tecnologia, de sua relação com o lado rotineiro da vida no campo e do desenvolvimento do trabalho rural. Assim, a inovação tecnológica na agricultura é vista como um elemento imprescindível, mostrando-se um dos caminhos mais favoráveis para o crescimento e o desenvolvimento das propriedades (LUCCA; DEPONTI, 2015).

Há uma proteção reconhecida nas atividades tecnológicas imateriais, o direito as concebe como conhecimentos tradicionais. Como ensina Resende (2013), a Convenção para a Salvaguarda do Patrimônio Cultural Imaterial estabelece que o patrimônio cultural e imaterial se manifesta por meio das tradições, expressões orais, expressões artísticas, práticas sociais, ritualísticas e festejos, conhecimentos e práticas relacionadas à natureza, ao universo, a técnicas artesanais e tradicionais.

A Convenção sobre a Diversidade Cultural, reconhece a importância dos conhecimentos tradicionais como fonte de riqueza material e imaterial, contributo positivo para o desenvolvimento sustentável, assim como a necessidade de assegurar sua adequada proteção e promoção (RESENDE, 2013).

Ensinam Bertoldi e Sposato (2012) que o conhecimento tradicional é componente intangível, imaterial da biodiversidade, sendo a informação ou prática individual ou coletiva de comunidade indígena ou local, com valor real ou potencial.

Esse componente compreende:

[...] desde técnicas de recursos naturais até métodos de caça e pesca, conhecimentos sobre os diversos ecossistemas e sobre propriedades farmacêuticas, alimentícias e agrícolas de espécies e as próprias categorizações e classificações de espécies de flora e fauna utilizadas pelas populações tradicionais. (SANTILLI, 2005, p. 192).

Também, se refere ao extrativismo, uso e conhecimento de fibras, sementes, óleos, resinas; ao conhecimento e manejo do solo, da água e sua função; a tecnologias de feitura de casas, instrumentos de trabalho (DIEGUES, 2001, p. 184). É sob esta percepção que se insere o debate nos processos de trabalho rural, em especial. A agricultura familiar, atualmente, é o maior segmento em número de estabelecimentos agrícolas, cuja significativa importância econômica, reflete no mundo todo.

Muitas vezes tem sido designada e caracterizada como "pequena propriedade", desempenhando um papel importante ao garantir a subsistência da família, distribuir renda e gerar postos de trabalho, ga- 
rantindo assim, o sustento de milhões de brasileiros. Isso porque a produção familiar se caracteriza pela pequena propriedade, pelo trabalho familiar e pelo uso de baixa tecnologia (BRUM; TRENNEPOHL, 2004).

Mas, pode-se afirmar que desde a sua existência até os dias atuais a agricultura familiar passou por profundas transformações, as quais modificaram completamente a sua realidade. Trata-se do fenômeno da modernização, que compreende mudanças nos métodos técnicos de produção, utilização de máquinas sofisticadas, insumos modernos e o processo de rotações de culturas, ou seja, diversos padrões introduzidos na agricultura, nos últimos anos, que provocaram alterações profundas na atividade produtiva (SILVA, 1998).

Observa-se que com o processo de modernização da agricultura ocorreu a mercantilização da produção, modificando completamente a realidade. As novas tecnologias foram pouco a pouco tomando o lugar da mão de obra humana e das técnicas rudimentares utilizadas, como por exemplo, os instrumentos de trabalho simples e de fabricação caseira ou local que foram substituídos por máquinas complexas, sofisticadas e de alto valor (BRUM, 2002).

A família agrícola trabalha de forma aberta, diferenciando-se do funcionamento de uma empresa capitalista. Por mais mercantilizada que seja a produção familiar não tem como pressupostos a taxa média de lucro e o pagamento da renda fundiária. Isso faz com que o núcleo de produção, o consumo e o seu vínculo com a terra não possuam uma característica eminentemente mercantil (LACERDA, 1985).

Para o produtor a lógica não é obter o lucro, mas sim conseguir manter a produção não gerando somente despesas. 0 que move o produtor familiar é a reprodução da sua unidade de produção como forma de garantia de sua sobrevivência enquanto unidade familiar (BASSO, 1993).

Segundo Brose (1999), para a agricultura familiar se fortalecer seria necessário que políticas públicas correspondentes possibilitassem aos agricultores familiares inserirem-se ativamente nos espaços econômicos dos quais estiveram historicamente excluídos. Hoje a agricultura é um dos mais importantes instrumentos de geração de emprego e renda, visto que políticas já inseridas no mercado minimizam a exclusão dos que se encontram em situações mais problemáticas.

Para Lucca e Deponti (2015) não se pode esquecer que a modernização gerou também aspectos negativos no campo como, por exemplo, êxodo rural, degradação do meio ambiente, dependência do setor agrícola ao setor industrial, desgaste do solo, inadequação tecnológica de pequenos agricultores e concentração da propriedade. A agropecuária brasileira, apesar das enormes potencialidades do país e avanços conquistados, ainda apresenta grandes problemas e desafios históricos, dentre eles a questão ambiental.

A agricultura sempre teve grande importância dentro da economia nacional. A complexidade do espaço agrário brasileiro permite refletir sobre diversos aspectos, de ordem econômica, política, social e cultural e enfoques teóricos aplicados no estudo das diferenças no interior desse espaço, destacando a realidade do trabalho familiar a partir dos estudos de caso.

Cabe uma sinalização crítica e reflexiva importante, o emprego de novas tecnologias no processo de produção agrícola como expressão marcante da modernização no campo gera poucos empregos e aumenta o número de trabalhadores rurais desempregados, ainda faz uso de formas precárias de trabalho "[...] o uso de tecnologia empregada significa a expulsão do trabalhador, desemprego o que 
significa força de trabalho excedente, e sem garantias de trabalho, portanto exploração intensiva das horas de trabalho" (CONCEIÇÃO, 2007, p.).

\section{MANEJO E O CULTIVO DA CASTANHA EM ITABAIANA-SE}

Esta pesquisa considerou um tema de estudo da agricultura brasileira inserido dentro da dinâmica da agricultura familiar e em crescimento na região Nordeste principalmente na última década: a castanha de caju. A cajucultura é uma atividade tradicional do Nordeste antes pouco comercializada, mas com o passar do tempo essa atividade foi se expandindo por todas as regiões e tornou-se uma das principais economias da região, principalmente com os fluxos de pessoas e capital sobre essas áreas produtoras (OLIVEIRA; CARNEIRO, 2011)

Em sua pesquisa, Costa (2010), reflete sobre o capital e a cajucultura e aduz que, seguindo esta lógica, a atividade da castanha de caju, produto de forte valor e aceitação no mercado, passa a ter o seu processo de produção, beneficiamento e comercialização sob o controle e lógica do modo de produção capitalista, é o agronegócio da castanha de caju que está alicerçado basicamente no processo de produção, de beneficiamento e de comercialização da castanha.

O capital para se espacializar no campo se traveste de várias formas e cria diferentes estratégias de exploração. 0 agronegócio se estabelece no campo como uma das estratégias do capital para manter o controle da produção agrícola camponesa a partir da mercadorização, pois no sistema capitalista tudo tende a se transformar em mercadoria para ser vendida e assim gerar lucro.

Dentro dessa lógica a atividade cultural da castanha de caju era realizada nos momentos de descontração, depois da safra do caju todos se reuniam ao redor do fogo para assar, quebrar e pelar a castanha no interior das propriedades camponesas, a castanha tinha uma valor simbólico e apreciativo destinada para o consumo, não tinha valor de troca, mas com a valorização do produto devido à procura no mercado, a atividade da castanha de caju se transforma em uma atividade econômica que gera emprego e produz riqueza no Nordeste brasileiro (COSTA, 2010)

A castanha de caju passa a ser uma mercadoria e nessa condição é vendida, mas não basta apenas ser vendida tem de garantir lucro, e esse lucro tem de ser cada vez maior como garantia da acumulação do capital. Para aumentar o lucro se faz necessário intensificar a exploração do trabalho na produção de mercadorias (COSTA, 2010)

A castanha de caju tem se constituído um produto de forte valor e aceitação no mercado mundial e nacional. No cenário mundial o Brasil se insere como o terceiro maior produtor de castanha de caju, perdendo apenas para o Vietnã e a Índia, neste contexto, a cajucultura é uma atividade de relevância social e econômica.

A região Nordeste domina a produção e o beneficiamento da castanha de caju, produto de forte valor econômico é o terceiro produto mais lucrativo na região. Na descrição de Costa (2010), o agronegócio da castanha de caju no Brasil se concentra na região Nordeste, onde gera divisas, empregos e rendas para a população expropriada trabalho na cidade e no campo.

0 estado de Sergipe tem destaque no cenário nacional no processo artesanal de beneficiamento da castanha, no entanto não se constituem áreas de interesse por não se inserirem estrategicamente 
na cadeia produtiva do agronegócio. O cajueiro constitui uma cultura agrícola de grande importância cultural e econômica para o Nordeste brasileiro.

Itabaiana é um município de destaque no estado de Sergipe, com mais de 90 mil habitantes e área de 336.685 km² (IBGE, 2017), localiza-se à região central do estado de Sergipe e clima predominantemente semiárido, ocupa posição importante na economia em razão do polo comercial municipal. Itabaiana limita-se com os seguintes municípios sergipanos: Ao norte com o município de Ribeirópolis, ao sul com os municípios de Areia Branca, a leste com Malhador e Riachuelo, a oeste Campo do Brito e a noroeste como os municípios de Frei Paulo e Macambira, a nordeste com Moita Bonita. Sua extensão territorial representa apenas 1,53\% do território sergipano e sua sede municipal se distancia da capital do estado, Aracaju, 56 km, por meio da BR-235 e BR-101 (IBGE, 2017)

Os povoados beneficiadores de castanha, Carrilho, Tabocas e Dendezeiro, estão localizados na porção sudoeste do município de Itabaiana, em Sergipe e se destacam como os mais importantes no processo de beneficiamento da castanha de caju. Todos eles estão próximos espacialmente e ligados por estradas secundárias não pavimentadas, destacando os aglomerados do Carrilho e de Tabocas, por serem mais estruturados e com o mínimo na oferta de serviços, como escola, posto de saúde e telefônico.

De acordo com os estudos de Costa $(2009 ; 2012)$, o Carrilho ainda apresenta um arruado não pavimentado, articulado por duas ruas menores. Os três aglomerados, objeto da pesquisa em tela, somam 1258 habitantes, praticamente todos eles dedicados ao beneficiamento da castanha de caju. Esses povoados economicamente diferenciam-se dos demais aglomerados rurais desse importante município sergipano, em função de não desenvolverem atividades voltadas à agricultura familiar e sim pela atividade da castanha de caju, orientada também da pecuária de corte e por estarem presentes, em seus arredores, às maiores pedreiras do estado, principalmente na produção do granito.

A castanha de caju, que passa por diversas fases de produção-beneficiamento, pode ser observada no Brasil basicamente em duas vertentes em seu aspecto produtivo. A primeira, pela formação de uma moderna cadeia produtiva, envolvendo produtores, beneficiadores e vendedores/exportadores do produto. Aspecto visualizado nos estados de maior produção da castanha, como os estados do Rio Grande do Norte e Ceará. E o segundo, pelo beneficiamento artesanal, com uso intensivo da mão de obra familiar, forte dependência do segmento fornecedor da matéria-prima e baixa inserção do componente tecnológico, com rebatimento negativo na produtividade do trabalho (COSTA, 2009; 2012).

Assim, para que esses agricultores familiares, que trabalham artesanalmente, obtenham renda suficiente para a sobrevivência da família, necessitam aumentar significativamente seu tempo de trabalho, inclusive contratando mão de obra extra, na medida em que a renda é obtida por cotas de produção e com entrega semanal do produto beneficiado.

Verificado pelo estudo realizado por Costa (2012) que a possibilidade de inserir novas técnicas no processo de produção, melhorando as condições e aperfeiçoando os rústicos instrumentos de trabalho, é de grande importância propositiva, vez que contribui na melhoria da renda individual e familiar desses trabalhadores. No mesmo sentido, define-se a necessidade de melhoria na gestão desses produtos, visto que existe perda da castanha no momento do beneficiamento e do transporte. Fato que colabora na diminuição do volume e da qualidade do produto, tendo como consequência à diminuição dos preços no atacado. 
Nos relatórios de Costa (2009; 2012), restou claro que a questão do beneficiamento da castanha de caju é inserida como uma das atividades mais tradicionais de emprego e renda em alguns municípios da microrregião agreste de Itabaiana-SE. Entretanto, do ponto de vista de seu processo de beneficiamento e de gestão, essas questões ainda merecem desenvolvimento e melhoria, visando auferir maior produtividade do trabalho familiar e com ele melhoria na renda.

Aspectos relacionados ao uso intensivo da mão de obra; ao uso artesanal de equipamentos de trabalho para torrefação, quebra e despeliculagem da castanha de caju, aliada a insalubridade do ambiente de trabalho, face a intensa fumaça produzida no processo de torrefação; bem como, da inexistência de equipamentos de proteção individual. Estes são alguns dos problemas enfrentados pelos trabalhadores, que aliam circunstancialmente atividade da pequena produção familiar com 0 beneficiamento da castanha de caju durante todo o ano (COSTA, 2009).

Desse modo, essa atividade tem dupla face contraditória. A primeira, apresentada pela frágil renda obtida por estes trabalhadores em uma semana intensiva de trabalho e a segunda, por ser a castanha um produto de alto valor mercadológico, cujo lucro não é transferido aos trabalhadores ou "assadores" da castanha de caju, particularmente no agreste de Itabaiana.

Assim, algumas singularidades da cadeia produtiva da castanha de caju em Itabaiana foram apresentadas pelas pesquisas de Costa (2009; 2012): 1- As relações de trabalho observadas na cadeia de produção da castanha de caju apresentam o uso da força de trabalho familiar em toda a sua extensão, sobretudo no beneficiamento; 2- As atividades agropecuárias são verificadas como atividades complementares no contexto do trabalho familiar da castanha de caju; 3- A articulação da cadeia produtiva da castanha de caju é realizada pelo intermediário.

O que demonstra que todo o trabalho, no contexto do capitalismo, tende a ser exploratório e desigual, separando quem trabalha de quem tem acesso ao poder, consequentemente, aquele que explora o trabalhador.

\section{APRESENTAÇÃO E DISCUSSÃO DOS RESULTADOS AS RELAÇÕES DE TRABALHO E PROBLEMAS NO BENEFICIAMENTO DA CASTANHA DE CAJU, AS ASSOCIAÇÕES E AS MINIFÁBRICAS}

Entre os povoados que beneficiam a castanha de caju se nota uma divisão do trabalho familiar determinada pelo sexo ou ainda por idade. Um indivíduo adulto do sexo masculino, muitas vezes o pai da família, é quem normalmente administra o processo e realiza o trabalho mais perigoso, a torrefação. Nesta etapa da produção, os incômodos do calor, da fumaça e do aroma são os problemas mais comuns.

O trabalho da mulher e dos jovens, em geral, consiste na quebra da castanha e na despeliculagem, além do trabalho da limpeza, da classificação, da pesagem e do ensacamento. No entanto, a depender da urgência imposta pelo intermediário ou até da necessidade da venda a varejo nos finais de semana, essas etapas do beneficiamento podem ser feitas com o trabalho de toda a família.

Por meio do trabalho de campo realizado por Costa (2012), foi verificado que, 53.33\% das famílias questionadas apresentam uma determinada divisão de trabalho que se fundamentam, como já 
mencionado, no assar, no quebrar e no despelar. Enquanto $43.33 \%$ dizem não haver divisão e outros $3,33 \%$ não opinaram.

Dos que disseram haver divisão de trabalho entre os membros da família se averigou que ela se configura por sexo, sendo que, do total de 77 homens, 27,27\% são quebradores de castanha, $25.97 \%$ são assadores e $14.28 \%$ são despeladores. Entre as mulheres, essa subdivisão de tarefas no beneficiamento da castanha se demonstrou da seguinte forma: $34.66 \%$ eram despeladoras, $28 \%$ eram quebradoras e $9.33 \%$ eram assadoras de Castanha.

Por esses números, trazidos à baila por Costa (2012), se constata que no processo de beneficiamento da castanha o homem tem a atividade principal, que é assar a castanha, como também, mostra que a mulher tem avançado nesse sentido. Todavia, a mulher tem como atividade principal o despelar da castanha.

Além da atividade da família, por vezes se contratam pessoas para esse trabalho. Das trinta famílias questionadas na área do foco da castanha se averiguou que cerca de $40 \%$ contratam mão de obra, como também, contam com o auxílio de $80 \%$ dos parentes no processamento da castanha (COSTA, 2012).

A jornada de trabalho também depende da quantidade de mão de obra que sua família dispõe para a atividade. Entretanto, na medida em que, praticamente, toda a família dedica-se ao processo de beneficiamento da castanha de caju, apenas eventualmente há necessidade de mão de obra contratada por ela. Esta necessidade ocorre, sobretudo, nos últimos meses do ano, em função da maior demanda do produto no mercado.

O levantamento do relatório desenvolvido por Costa (2012) verificou que $87 \%$ dos questionados dedicam mais de oito horas diárias de trabalho com o processamento da castanha, sendo que apenas $13 \%$ ficam com carga inferior a essa, decorrente de problemas familiares, de trabalharem com agricultura de subsistência e comercialização da castanha.

Costa (2012) destaca que essa jornada de trabalho se integra um aspecto cultural, o fato de eles só trabalharem com o beneficiamento da castanha da terça-feira ao sábado. A segunda-feira, para esses trabalhadores, "é o dia da ressaca" ou "o dia de brincar e conversar". E assim, apesar de sempre ser ressaltado por eles que a castanha de caju tem "peso de ouro", como quem resiste ao apelo de produzir o máximo valor, mesmo que sacrificando o tempo de viver, este costume perpetua no cotidiano local.

Além disso, somam-se a esses aspectos o modo de processamento da castanha, que é todo manual, pois não há entre seus trabalhadores, equipamentos elétricos para torrefação, quebra e despelagem da castanha. Esta atividade pode ocorrer tanto em casa como fora, a depender da etapa que esteja sendo executada, ou da disponibilidade de espaço.

Para o manuseio desse produto muitos têm montado uma infraestrutura muito humilde, mas necessária para seu conforto, no caso dos questionados, $76.66 \%$ construíram algumas benfeitorias do tipo tendas com palhas, com telhas e a de galpões.

Interessante colocação de Costa (2009) se dá quanto aos instrumentos mais utilizados nas unidades beneficiadoras de castanha destacam-se: faca (96.66\%); Instrumento tidos como apropriado para assar (93,33\%); vara (60\%); caqueiro de alumínio (46,66\%); seguidos de fogão (33,33\%); caqueiro de barro (20\%); instrumento de madeira (16,66\%), luva (10\%) e lenha $(6,66 \%)$. 
Em meio aos beneficiadores que utilizam lenha, apenas três disseram se utilizar de pedaços de madeira encontrados na própria propriedade como forma de sustentar inicialmente a chama do fogo, que logo depois é alimentada pela casca da castanha. Essa casca, que não apresentava serventia agora sua utilização como combustível mostra-se como uma maneira de expressar a sustentabilidade que o beneficiamento apresenta, além de ser uma forma de garantir a subsistência das famílias nos três povoados.

Outra verificação importante do relatório de Costa (2009) diz respeito a castanha, que segundo as 22 famílias que a assam, leva em média de 3 a 10 minutos para ficar pronta para o processo de quebra. 0 volume médio colocado por vez varia de meio quilograma a 3 quilogramas.

Entre os beneficiadores é comum o trabalho começar pela madrugada, em horários que variam das 02:00 as 05:00 horas da manhã. Eles justificam esse horário pelo fato de ser fresco, evitando o mormaço do dia que é intensificado no assar da castanha e uma forma de terminar mais cedo, cumprindo o acerto estabelecido com o intermediário.

Entre os trinta beneficiadores de castanha de caju questionados, 83,33\% apontaram haver espécies de castanha, denominadas de grande e de pequenas, feias e bonitas, sendo quase unânime entre eles a opinião de que a melhor castanha para assar e pelar seja a do Piauí. No processo de assar, eles apontaram como determinantes no reconhecimento da castanha assada, o cheiro e a tonalidade da castanha.

Chama atenção ainda, nos estudos de Costa $(2009 ; 2012)$ no processo de beneficiamento desse produto, tanto na etapa da torrefação como nas demais etapas, a inexistência do uso de equipamento de proteção individual, sobretudo equipamentos para a proteção das mãos e dos olhos. A perda das digitais, nesse sentido, está se tornando um dos grandes problemas daqueles trabalhadores, principalmente entre os mais velhos.

E este problema nas mãos está relacionado ao manuseio da castanha sem luvas e em função das características do produto, que apresenta certa oleosidade. Todavia, tais trabalhadores já não apontam a fumaça como grande problema, pois apenas $53.33 \%$ dizem terem danos provocados pelo assar da castanha, como, a ardência nos olhos, falta de ar, tosse, alergias e gripes. Além disso, fora identificado problemas de coluna em função da postura inadequada no momento de trabalho.

Na região da castanha não há uma organização entre os próprios beneficiadores a fim de gerar benefícios para os seus associados, a não ser no povoado Carrilho. Neste povoado a associação fora fundada no ano 2000 e denominada de Associação dos Beneficiadores e Vendedores de Castanha do Povoado Carrilho. Ela é composta por presidente, vice-presidente e tesoureiro eleitos por trinta famílias associadas para um mandato de dois anos, visa à organização dos trabalhadores locais e à melhoria da qualidade do produto para um maior acesso ao mercado.

A Associação tem estatuto próprio, que a define como uma Entidade Jurídica de Direito Privado sem fins lucrativos. Esse estatuto visa a regulamentação das ações dos castanheiros do Povoado Carrilho, tanto na compra como na venda da castanha no povoado, bem como na fiscalização do preço da amêndoa no mercado. Santana (2007), por sua vez, observa que após a criação da Associação, a comercialização da castanha de caju do Carrilho foi expandida para outros estados brasileiros, a exemplo de Alagoas, Bahia, Rio de Janeiro e São Paulo (COSTA, 2012). 
Além disso, a associação surgiu pela ação de onze estudantes da própria comunidade, que pelos obstáculos encontrados em estudar no turno noturno e em virtude do horário que levantam para o trabalho acabaram se integrando em prol de um objetivo comum, a necessidade de melhorar as condições de trabalho. 0 primeiro projeto neste sentido, denominado de “Adequação de Galpões da Usina de Beneficiadores de Castanha” (protocolo, n 1861), foi aprovado pelo Projeto de Combate à Pobreza Rural (PCPR) no ano de 2003 após o pleito da Associação dos Moradores e Amigos do Povoado Carrilho. Sua primeira etapa, financiada pela Empresa de Desenvolvimento Sustentável do Estado de Sergipe Pronese (protocolo n 439 ) e Banco Mundial, visava contemplar inicialmente 40 famílias (COSTA, 2012).

A partir desse projeto foi edificada uma construção composta por três galpões e uma área com quatro fornos. Esta se encontra desativada em razão de apresentar-se inadequada às condições exigidas para a execução do trabalho e, inadequada ainda, ao modo de beneficiamento da castanha em Sergipe, ou seja, a torrefação. 0 empreendimento, fazendo uso de equipamentos apropriados ao modelo de beneficiamento da castanha em outros estados do Nordeste, o cozimento, não atenderia as reais necessidades configuradas no povoado.

Deve-se ressaltar, todavia, que, em 2005, uma nova tentativa de colocar em operação a minifábrica do Carrilho é observada, desta feita, por meio do projeto encaminhado pela Associação de Beneficiadores e Vendedores de Castanha do Povoado Carrilho, ao qual foi negado novo investimento em virtude dos problemas com a infraestrutura. Tal tentativa visava concluir a etapa de edificação da minifábrica, colocando nela os equipamentos conforme as adequações do trabalho realizado no próprio povoado (COSTA, 2012).

Atualmente, a minifábrica constitui-se um espaço abandonado pela associação e que é utilizado por alguns poucos beneficiadores de castanha, que a compram e a armazenam no galpão. Sua área está totalmente tomada por vegetação e ocupada por marimbondos vermelho.

\section{DISCUSSÃO: OS IMPACTOS DA MODERNIZAÇÃO DAS NOVAS TECNOLOGIAS NO MANEJO DA CASTANHA EM ITABAIANA-SE}

Definido como o "território da castanha de caju em Sergipe”, o município de Itabaiana, um importante polo regional no desenvolvimento da agricultura familiar e onde a produção da castanha é tradicional, apresenta um conjunto de povoados que se destaca no beneficiamento da amêndoa no estado, destacando: Carrilho, Dendezeiro e Tabocas.

De acordo com Costa (2009; 2012), nesses povoados o beneficiamento da castanha de caju é desenvolvido pela mão de obra familiar, quase sempre agricultor familiar e constitui a principal atividade na formação da renda familiar. A atividade castanheira, dessa forma, participa como um elemento importante na renda familiar, contribuindo na melhoria das condições de vida desses trabalhadores familiares.

Além das diferenças entre a atividade castanheira desenvolvida em Sergipe e a atividade desenvolvida nas demais áreas produtoras da amêndoa do território brasileiro, a análise da inserção do trabalho familiar no beneficiamento da castanha de caju no estado expõe as contradições e os problemas estruturais observados na sua cadeia produtiva, que apresenta as seguintes características, baseadas no que fundamenta o relatório de Costa (2012): 
I. ela é incompleta em razão da inexistência da lavoura comercial do cajueiro;

II. ela apresenta o predomínio da mão-de-obra familiar somente no processo de beneficiamento, que é realizado quase sempre próximo à residência da família;

III. a etapa de beneficiamento da castanha de caju opera como divisão determinada pelo sexo e pela idade;

IV. o processo artesanal domina o beneficiamento, com uso de instrumentos rústicos de trabalho e inexistência do uso de equipamento de proteção individual;

V. ela apresenta uma exploração da força de trabalho familiar por intermediários que tanto compram e fornecem o produto in natura para o beneficiamento como adquirem a amêndoa processada e a comercializam;

VI. nela, a intensidade da produção de castanha pelo beneficiador apresenta-se variável durante $o$ ano, em função da oferta da matéria-prima pelo fornecedor;

VII. a jornada de trabalho do beneficiador da castanha é flexível, em função da oferta da matéria-prima pelo fornecedor e da quantidade de membros da família ocupados com a atividade, restrita, todavia, por ele da terça-feira ao sábado;

VIII. nela, apenas eventualmente há contratação de mão-de-obra para o beneficiamento da castanha pelo trabalhador familiar, geralmente parente ou conhecidos.

IX. a atividade abastece o mercado regional, através do intermediário no segmento atacadista e com a participação do beneficiador no segmento do varejista;

$X$. o pagamento que o intermediário faz ao beneficiador da castanha pode ocorrer sob a forma de diárias ou de empreitadas, sendo que as duas formas admitem o uso do dinheiro ou o uso da própria castanha.

Desse modo, em Itabaiana o processo de beneficiamento da castanha de caju envolve diversas etapas: a torrefação da castanha in natura, a quebra da casca, a despeliculagem, a limpeza, a classificação, a pesagem e, por fim, o ensacamento da amêndoa. 0 beneficiamento ocorre de forma artesanal e é realizado quase sempre no fundo ou ao lado da residência da família, com uso de instrumentos rústicos de trabalho.

A importância de se agregar tecnologias sociais nesse processamento fortalece na integração comunitária; na geração de procedimentos a baixos custos, em pequena ou média escala, com simplicidade; na geração de efeitos positivos frente à necessidade dos trabalhadores. Tal agregação justifica-se na busca por melhorias, principalmente no aspecto social, econômico e ambiental (COSTA, 2009; 2012).

Por conseguinte, a implementação de tecnologias sociais no povoado Carrilho tem se utilizado de características disponíveis na sociedade, buscando gerar bem-estar social e resolver pendências expostas a partir da edificação de estrutura para a quebra e torrefação da castanha de caju. Para tanto, fora reformada a tenda e construída mesa com cadeiras rebaixadas, a fim de manter eficiência ergonômica e chaminé, que tem contribuído para a descentralização de fumaça durante o período de torrefação (COSTA, 2009; 2012).

Assim, o intuito foi promover o crescimento da renda, das condições de trabalho dos beneficiadores e de encaminhar tal projeto para a institucionalização de uma política voltada para esse importante segmento social do meio rural sergipano. Essa institucionalização já tem sido negociada 
juntamente ao Banco do Brasil. Contudo, mais do que linhas de financiamento, o grupo de Pesquisa em questão juntamente com a comunidade do Povoado Carrilho e a Associação dos Beneficiadores e Vendedores de Castanha, tem perspectiva de viabilizar o projeto com a intervenção do Grupo Votorantim, que previu a edificação de 50 novas tecnologias sociais (proposta bem recente, 2012). Além disso, a Empresa do Desenvolvimento Sustentável do Estado de Sergipe (PRONESE) tem voltado a atuar na comunidade, na busca revitalizar a minifábrica (COSTA, 2009; 2012).

Logo, apesar da inserção de tecnologias com experiências individuais, as cinco práticas tem surtido efeitos positivos frente à reorganização da comunidade por melhorias das condições de trabalho e renda; por exercício de pressão política sobre a prefeitura local, que passa a impor infraestrutura necessária na transformação da comunidade em ponto turístico no Estado de Sergipe; por estimular a luta desses trabalhadores junto a agências de financiamento.

E, observa ao final, ambos os estudos de Costa $(2009 ; 2012)$ que tais aspectos se inserem no fortalecimento e ampliação da prática beneficiadora de Castanha do povoado Carrilho em Itabaiana; podendo até propor a criação de novos territórios da castanha em outros aglomerados rurais, nos quais esse produto seja o principal elo de reprodução econômica das famílias.

\section{CONSIDERAÇÕES FINAIS}

As relações de trabalho, bem como as identidades dos trabalhadores e o perfil dos empregadores, mudaram de forma muito dinâmica ao longo dos anos. Inúmeras são as novas categorias de relações trabalhistas possíveis no contexto da sociedade atual que se estabelecem, novas espécies de serviços e trabalhadores diferenciados surgem na atual sociedade. Dentre as inúmeras modificações ocasionadas às relações de trabalho, é possível se destacar o surgimento da tecnologia, responsável por novos arranjos e novas formas de trabalho e de forma correlata, da necessidade de normas trabalhistas capazes de responder aos anseios do jurídicos advindos deste contexto.

O desenvolvimento do trabalho, as ferramentas, as habilidades e competências, os locais onde o trabalho ocorre têm se tornado cada vez mais tecnológicos, mudando completamente a forma de desenvolvimento do trabalho e construindo a cada dia, uma nova realidade para os empregados e empregadores. É necessário se repensar a forma clássica de disposição da relação de emprego, considerando assim, as transformações tecnológicas do trabalho.

As tecnologias sociais buscam a inclusão social e melhoria das condições de vida das populações, fortalecendo a promoção do bem-viver e o cuidado coletivo com a vida na terra e em nosso país. Nesse sentido, o tema das novas tecnologias para um trabalho digno vem ganhando uma importância muito grande no debate sobre a construção de uma sociedade mais justa, igualitária, solidária e sustentável.

No momento em que o homem se utiliza de suas técnicas para modificar o espaço natural de acordo com suas necessidades, planta, colhe e trabalha a sua maneira, cria suas próprias relações de trabalho e designa o desenvolvimento econômico de uma região.

O homem utiliza de seu poder de transformar o espaço para elevar o desenvolvimento de uma dada área. Assim, contribui não somente para si, mas para toda uma sociedade dependente 
dessas transformações espaciais. A partir das tecnologias utilizadas para o desenvolvimento do campo ou de toda uma rede urbana fornecida pelo capitalismo, sendo o resultado direto de uma modernização, capaz de aumentar sua margem de lucro e manter seu foco sobre uma prosperidade de crescimento.

Essencial e fundamental à esta pesquisa foram os relatórios do Grupo de Pesquisa sobre transformações no rural, ligados ao Núcleo de Pós-Graduação em Geografia da UFS, e liderados por Costa (2009; 2012). Em consequência de seus levantamentos, a partir destas referências é que este último capítulo apresenta reflexões sobre o manejo da castanha em Itabaiana-SE. Foi possível partir para uma intervenção de campo que conduziu a reflexão a um locus específico com um olhar etnográfico, lançado sobre os povoados de Carrilho, Dendezeiro e Tabocas, no município de Itabaiana, estado de Sergipe.

No município pesquisado, há massivamente a presença do segmento familiar composto de trabalhadores envolvidos no beneficiamento da castanha de caju, as expectativas de melhorias, por via das políticas públicas, revelam sua fragilidade como proposta de desenvolvimento rural. 0 presente trabalho é fruto de uma leitura das mudanças que têm ocorrido no mundo do trabalho e da falta de política pública eficaz, que estão presentes na atividade de manejo da castanha de caju na comunidade Carrilho, no município de Itabaiana, localizado no Agreste Central do estado de Sergipe, Nordeste-Brasil.

Percebeu-se que o trabalho desenvolvido pelos “castanheiros” é bastante frágil, no que diz as mudanças sociais e econômicas no município de Itabaiana, ora pela necessidade de políticas públicas capazes de promover a assistência social na melhoria das condições de vida, ora em garantir uma estabilidade financeira e acessibilidade em termos de segurança no trabalho, dada pelas falta de políticas públicas existentes.

A precarização do trabalho é um desses efeitos indesejados, pela própria ineficiência na implantação, como já foi destacado anteriormente, que não garante desenvolvimento econômico e social das famílias, submetendo-as aos reveses do modo de produção capitalista, forçando-os a buscarem complementar a renda familiar em diversas atividades não agrícolas e desprovidas de quaisquer equipamentos de segurança e de saúde. Uns dos principais problemas enfrentados pela comunidade é o trabalho informal, os trabalhadores do mundo e de Carrilho, pequeno povoado rural no município de Itabaiana-SE, submeterem-se as formas de trabalho precarizado.

A modernização não pode ser a aniquilação dos postos de trabalho que dependem da cajucultura familiar nos povoados de Carrilho, Dendezeiro e Tabocas, no município de Itabaiana, estado de Sergipe. A reflexão que se apresenta neste estudo, visa contribuir para a reflexão do modo de trabalho no manejo da castanha de caju, tendo na modernização tecnológica uma forma de melhoria e qualidade de vida aos trabalhadores envolvidos com a cajucultura.

Analisou-se in loco como se opera o manejo da castanha de caju, em especial, junto a própria comunidade familiar que trabalham com a cajucultura nos povoados de Carrilho, Dendezeiro e Tabocas, no município de Itabaiana, estado de Sergipe. No experimento de verificação em campo de pesquisa do beneficiamento da castanha de caju, foi possível identificar todos 
as complexidades das atividades e as condições indignas do tipo de trabalho na reflexão aqui apresentada.

Constatou-se que toda a cadeia produtiva de extração do caju é familiar e são utilizadas tecnologias quase primitivas de trabalho, sem o menor cuidado com a saúde dos trabalhadores, bem como a clareza de condições indignas de trabalho de crianças e adolescentes. Não existem condições mínimas de trabalho digno.

A ausência de ações que viabilizem condições dignas, como a viabilização de uma reforma agrária para aqueles que vivem no espaço rural ou políticas que assegurem a autonomia dos trabalhadores, expressa o comprometimento do Estado no atual estágio das relações capitalistas em resolver os problemas sociais. Assim, evidenciou-se o principal objetivo desta pesquisa, que é abordar a urgência de se (re)pensar o trabalho rural sob a ótica das novas tecnologias sob o viés do trabalho digno na contemporaneidade.

\section{REFERÊNCIAS}

AMARAL, Ana Iris Galvão. Direito fundamental ao trabalho digno: o papel do estado na efetivação da tutela. In: BELLINETTI, Luiz Fernando; RIBEIRO, Luiz Gustavo Gonçalves; VEDOVATO, Luis Renato. Eficácia de direitos fundamentais nas relações do trabalho, sociais e empresariais, 1. Anais..., Florianópolis: CONPEDI, 2016.

ANTUNES, Paulo Bessa. Meio ambiente do trabalho. Revista de Direitos Difusos, Direito Ambiental do Trabalho, São Paulo: Editora Esplanada, v. 5, p. 1971-1979, set.-out. 2002.

ARAÚJO. José Carlos. Transformações no conceito de trabalho. In: VIDOTTI, Tárcio José; GIORDANI, Francisco Alberto da Motta Peixoto (Coord.). Direito coletivo do trabalho em uma sociedade pósindustrial. São Paulo: LTr, 2003.

AUGUSTIN, Sérgio; MARTINI, Simone. A crise da causalidade e a responsabilidade ambiente na sociedade de risco. In:SPAREMBERGER, Raquel Fabiana Lopes. 0 direito na sociedade de risco: dilemas e desafios socioambientais. Caxias do Sul, RS: Plenum, 2009.

BARBOSA, Magno Luiz. O trabalho, o avanço tecnológico e o direito do trabalhador à desconexão. In: BARBOSA, Magno Luiz; BRITO, Cristiano Gomes de. Temas contemporâneos de direito empresarial do trabalho. São Paulo: LTr, 2015. p. 46-53

BARROS, Alice Monteiro de. Curso de direito do trabalho. 2. ed. São Paulo: LTr, 2006.

BARROSO, Luís Roberto. A dignidade da pessoa humana no direito constitucional contemporâneo: natureza jurídica, conteúdos mínimos e critérios de aplicação. Versão provisória para debate público. Mimeografado, dezembro de 2010. 
BESSA, Leonardo Rodrigues Itacaramby. Meio Ambiente de trabalho enquanto edireito fundamental, sua eficácia e meios de exigibilidade judicial. Justiça do Trabalho, Porto Alegre, Ano 26, n. 312, p. 16-26, dez. 2009.

BOMFIM, Vólia. Princípios trabalhistas, novas profissões, globalização da economia e flexibilização das normas trabalhistas. Niterói: Impetus, 2010.

BRASIL. Decreto-Lei n 5.452, de $1^{\circ}$ de maio de 1943. Aprova a Consolidação das Leis do Trabalho. 1943.

BRASIL. Constituição (1988). Constituição da República Federativa do Brasil. Brasília-DF, Senado, 1998.

BRASIL. Lei 10.406, de 10 de janeiro de 2002. Institui o Código Civil Brasileiro. 2002.

CAMILO, Adélia Procópio. Meio ambiente do trabalho como direito fundamental e responsabilidade civil do empregador. In: ANDRADE, Everaldo Gaspar Lopes de; CARVALHO NETO, Frederico da Costa; SCHWARZ, Rodrigo Garcia. Direito do trabalho e meio ambiente do trabalho I. Florianópolis: CONPEDI, 2015.

COMISSÃO Mundial sobre Meio Ambiente e Desenvolvimento. Nosso futuro comum. Rio de Janeiro: Fundação Getúlio Vargas, 1991.

CONCEIÇÃO, 2007.

COSTA, José Eloízio. A inserção de tecnologias de gestão e de processo no beneficiamento da castanha de caju no agreste de Itabaiana-SE. Grupo de Pesquisa sobre Transformações no Mundo Rural, Universidade Federal de Sergipe - UFS, 2012.

COSTA, José Eloízio. O trabalho familiar no processo de beneficiamento da castanha de caju em Sergipe: o caso do município de Itabaiana -SE. Grupo de Pesquisa sobre Transformações no Mundo Rural, Universidade Federal de Sergipe - UFS, 2009.

COSTA, Katinei Santo. 0 agronegócio da castanha de caju: o discurso do velho/novo mundo de desenvolvimento econômico no campo. 2010. Dissertação (Mestrado) - PPGEO/UFS, 2010.

DELGADO, Gabriel Neves. Direito fundamental ao trabalho digno. 2. ed. São Paulo: LTr, 2016.

FELICIANO, Guilherme Guimarães. Meio ambiente do trabalho - aspectos gerais e propedêuticos.

Síntese Trabalhista, v. 14, p. 122-153, 2002. 
FELTEN, Maria Cláudia. A proteção dispensada ao meio ambiente do trabalho à luz do princípio da dignidade da pessoa humana. Revista Trabalho e Meio Ambiente, Caxias do Sul, v. 5, n. 8, p. 157168, jan. 2007.

FERRARI, Irani; NASCIMENTO, Amauri Mascaro; MARTINS FILHO, Ives Gandra; COSTA, Armando Cassimiro. História do trabalho, do direito do trabalho e da justiça do trabalho. São Paulo: LTr, 1998.

FERREIRA, Ivette Senise. O meio ambiente do trabalho e sua relação com os direitos fundamentais da pessoa humana. Revista do Advogado, São Paulo, Ano 24, n. 76, p. 47-55, jun. 2004.

FERREIRA JÚNIOR, Mario. Saúde no trabalho: temas básicos para o profissional que cuida da saúde dos trabalhadores. São Paulo: Roca, 2000.

FIGUEIREDO, Guilherme José Purvim de. Direito ambiental e a Saúde dos Trabalhadores. São Paulo: LTr, 2000.

FIGUEIREDO, Guilherme José Purvim de. Direito ambiental e a saúde dos trabalhadores. 2. ed. São Paulo: LTr, 2006.

FIGUEIREDO JÚNIOR, Hugo Santana. Desafios para a cajucultura no Brasil: o comportamento da oferta e da demanda da castanha de caju. Revista Econômica do Nordeste, Fortaleza, v. 37, n. 4, out.-dez. 2006.

GAMBA, Juliane Caravieri Martins. Dignidade do trabalhador e políticas públicas: perspectivas no âmbito do Estado ético. In: PIOVESAN, Flávia; CARVALHO, Luciana Paula Vaz de (Coord.). Direitos Humanos e direito do trabalho. São Paulo: Atlas, 2010.

GOMES, Daniela Vasconcellos. A solidariedade social e a cidadania na efetivação do direito a um meio ambiente ecologicamente equilibrado. Revista Direito e Liberdade, v. 3, n. 1, p. 175-183, set. 2006.

GOMES, Fábio Rodrigues. 0 direito fundamental ao trabalho: perspectivas histórica, filosófica e dogmático-analítica. Rio de Janeiro: Lumem Juris, 2008.

GROTT, João Manoel. Meio ambiente do trabalho: a salvaguarda do trabalhador. Curitiba: Juruá, 2003.

INTERNATIONAL Labour Organization. Freedom of Association. A worker's education manual. Second (revised) edition. Geneva: ILO, 1987. 
JESUS, Edésio Alves de; SANTOS, Leandro de Jesus. Políticas públicas e a análise do trabalho precário no beneficiamento da castanha de caju - no município de Itabaiana-SE. Encontro Nacional de Geografia Agrária, Uberlândia-MG, 2012. Anais..., Uberlândia-MG, 15 a 19 de outubro, 2012.

LEITE, Carlos Henrique Bezerra. Curso de direito do trabalho. 7. ed. São Paulo: Saraiva, 2016.

LEITE, Roberto Basilone. Meio ambiente do trabalho e motivação. A ecologia do trabalho como instrumento de equilíbrio e de produtividade. Revista Jurídica do Ministério Público Catarinense, Florianópolis, v. 4, n. 10, p. 69-85, set.-dez. 2006.

LUCCA, Emerson Juliano; DEPONTI, Cidonea Machado. A tecnologia e a diversificação como ferramenta de apoio ao desenvolvimento agrícola. Globalização em Tempos de Regionalização Repercussões no Território Santa Cruz do Sul-RS, Brasil, 9 a 11 de setembro de 2015

MAIOR, Jorge Luiz Souto. 0 Direito do Trabalho como instrumento de justiça social. São Paulo: LTR, 2001. p. 20.

MANUS, Pedro Paulo Teixeira. Direito do trabalho. 14. ed. São Paulo: Atlas, 2012.

MARQUES, Christiani. A proteção ao trabalho penoso. São Paulo: LTr, 2007.

MELO, Raimundo Simão de. Segurança e meio ambiente do trabalho: uma questão de ordem pública. Revista Coad-Adv - Seleções Jurídicas, Rio de Janeiro: Coad, n. 4, 1996.

MELO, Raimundo Simão de. Dignidade humana e meio ambiente do trabalho. Boletim Científico da Escola Superior do Ministério Público da União, Brasília, Ano 4, n. 14, p. 87- 108, jan.-mar. 2005.

MELO, Raimundo Simão de. Direito ambiental do trabalho e a saúde do trabalhador:

responsabilidades legais, dano material, dano moral, dano estético, indenização pela perda de uma chance, prescrição. 3. ed. São Paulo: LTr, 2008.

MELO, Sandro Nahmias. Meio ambiente do trabalho: direito fundamental. São Paulo: LTr, 2001

MIRAGLIA, Lívia Mendes Moreira. Trabalho escravo contemporâneo: conceituação à luz do princípio da dignidade da pessoa humana. 2. ed. São Paulo: LTR, 2015.

MORIN, Edgar; KERN, Anne Brigitte. Terra-Pátria. Tradução de Paulo Neves da Silva. Porto Alegre: Sulina, 2011. 
OLIVEIRA, Christiana D’Arc Damasceno. (0) Direito do trabalho contemporâneo.

São Paulo: LTr, 2010.

OLIVEIRA, Lourival José de et al. Os princípios do direito do trabalho frente ao avanço tecnológico. Unopar Cientício. Ciência Jurídica Empresarial, Londrina, v. 3. n. 1. p. 53-59, mar. 2002.

OLIVEIRA, Sebastião Geraldo de. Proteção jurídica à saúde do trabalhador. 6. ed. São Paulo: LTr, 2011.

ORGANIZAÇÃO Internacional do Trabalho. Negociações coletivas. Tradução de Sandra Valle. São Paulo: LTr; DF: OIT, 1994.

ORGANIZAÇÃO Internacional do Trabalho. Normas internacionais de trabalho e programas da OIT em matéria de população. Tradução de Edílson Alkmim. Brasília: Positiva ,1994.

PESSOA, Flávia Moreira Guimarães. Relações de trabalho na sociedade contemporânea. São Paulo: LTr, 2009.

PIOVESAN, Flávia. Direitos humanos e o direito constitucional internacional. 7. ed. São Paulo: Saraiva, 2006.

PIOVESAN, Flávia; CARVALHO, Luciana Paula Vaz de (Coord.). Direitos humanos e direito do trabalho. São Paulo: Atlas, 2010.

RAMAZZINI, Bernardino. As doenças, os trabalhadores. Tradução de Raimundo Estrela. 3. ed. São Paulo: Fundacentro, 2000.

ROBERTI, Eduardo Torres; MORAES JÚNIOR, Ariel Salete de. Significações para o Trabalho na PósModernidade. Revista de Direito Fundamentais nas Relações do Trabalho, Sociais e Empresariais. Curitiba, v. 2, n. 2, p. 130-146, jul.-dez. 2016.

ROCHA, Júlio César de Sá da. Direito ambiental e meio ambiente do trabalho: dano, prevenção e proteção jurídica. São Paulo: LTr, 1997.

ROCHA, Júlio César de Sá da. Direito Ambiental e meio ambiente do trabalho: considerações sobre o ambiente de trabalho rural e a questão dos agrotóxicos. In: VARELLA, Marcelo Dias; BORGES, Roxana Cardoso Brasileiro (org.). O novo em direito ambiental. Belo Horizonte: Del Rey, 1998.

ROCHA, Samir Vaz Vieira; AMARAL, Ana Iris Galvão. Os desafios para garantia do trabalho digno: uma análise das mutações das relações trabalhistas na sociedade globalizada. In. SANTOS, Jackson 
Passos; VILLATORE, Marco Antônio César; CECATO, Maria Aurea Baroni. Direito do trabalho e meio ambiente do trabalho I. Florianópolis: CONPEDI, 2017.

ROMITA, Arion Sayão. Direitos fundamentais nas relações de trabalho. São Paulo: LTr, 2007.

ROSSIT, Liliana Allodi. 0 meio ambiente de trabalho no direito ambiental brasileiro. São Paulo: LTr, 2001.

SILVA, José Antônio Ribeiro de Oliveira. A saúde do trabalhador como um direito humano: conteúdo essencial da dignidade humana. São Paulo: LTr, 2008.

SILVA, Marco Aurélio Dias; MARCHI, Ricardo. Saúde e qualidade de vida no trabalho. São Paulo: Best Seller, 1997.

SIRVINSKAS, Luiz Paulo. Manual de direito ambiental. 10. ed. rev. atual. e ampl. São Paulo: Saraiva, 2012.

SOUSA, Otávio Augusto Reis de. Nova teoria geral do direito do trabalho. São Paulo: LTr, 2002.

SOUTO MAIOR, Jorge Luiz. 0 direito do trabalho como instrumento de Justiça Social. São Paulo: LTr, 2000

SUSSEKIND, Arnaldo. Instituições de direito do trabalho. 21. ed. São Paulo: LTr, 2003.

TIMBÓ Maria Santa Martins; EUFRÁSIO, Carlos Augusto Fernandes. O meio ambiente do trabalho saudável e suas repercussões no Brasil e no mundo, a partir de sua evolução histórica. Pensar, Fortaleza, v. 14, n. 2, p. 344-366, jul.-dez. 2009.

WOLD, Chris. Emergência de um conjunto de princípios destinados à proteção internacional do meio ambiente. In: Princípios de direito ambiental: na dimensão internacional e comparada. Belo Horizonte: Del Rey, 2003.

ZANELLA, Andréia Pereira. A dignidade da pessoa humana nas relações de trabalho. In: Direito do trabalho: reflexões atuais. Curitiba: Juruá, 2007. 
1 Mestre em Direitos Humanos - UNIT-SE; Especialista em Teorias do Estado e Direito Público - UNIT-SE; Graduado em Direito - UNIT-SE; Advogado.

E-mail: alexandroargolo@gmail.com

2 PhD em Estudos Internacionais, Universidade de Deusto, Espanha; Pós-doutorado em Políticas Públicas, Universidade Federal do Paraná; Mestrado em Direitos Humanos, Universidade Tiradentes - UNIT; Foi Researcher Marie Curie Action, Initial Network SPBuild (Comissão Europeia); Professor titular. E-mail: espinoza.fran@gmail.com 